REVISTA X, Curitiba, volume 13,n.1,p. 141-160, 2018.

Dossiê Especial: Português como Língua Adicional em contextos de minorias:

(co)construindo sentidos a partir das margens

BIZON \& DINIZ (Orgs.)

\title{
REFLEXÕES SOBRE O ENSINO DE PORTUGUÊS COMO LÍNGUA ADICIONAL NO ÂMBITO DO PROGRAMA DE ESTUDANTES-CONVÊNIO DE GRADUAÇÃO (PEC-G): ACOLHIMENTO DE ESTUDANTES E FORMAÇÃO DE PROFESSORES
}

\begin{abstract}
Reflexions On The Teaching Of Portuguese As An Additional Language In The Context Of The Exchange Program For Undergraduate Students (PEC-G): Students' Welcoming And Teachers' Development
\end{abstract}

Marcela Dezotti CÂNDIDO, UFMG ${ }^{1}$

\begin{abstract}
RESUMO: Há mais de cinquenta anos, o governo brasileiro mantém, por meio do Programa de Estudantes-Convênio de Graduação (PEC-G), acordos com países em desenvolvimento, oferecendo vagas em cursos de graduação em universidades brasileiras para estudantes das nações conveniadas. Como parte do convênio, oferece cursos de Português como Língua Adicional (PLA) para estudantes oriundos de países que não possuem posto aplicador do Certificado de Proficiência em Língua Portuguesa para Estrangeiros (Celpe-Bras). A partir do relato de experiência de uma das professoras de PLA para o pré-PEC-G, este artigo problematiza questões referentes ao acolhimento dos conveniados ao programa, além de buscar desconstruir imagens negativas geralmente atribuídas aos estudantes do PEC-G. Por fim, discutiremos algumas experiências positivas com relação à formação docente. $\mathrm{O}$ relato destaca diferenças entre esse programa e outros convênios de intercâmbio, aponta de quem é, muitas vezes, a maior responsabilidade junto ao PEC-G e expõe possíveis ações que têm potencial de promover vivências de aprendizagem positivas para os estudantes e de proporcionar experiências significativas relacionadas à formação do professor. Ao empreender este estudo, buscamos conhecer mais a fundo as particularidades do convênio PEC-G, desconstruir visões que essencializam os estudantes desse grupo e discutir maneiras de como lidar com as especificidades do programa, sobretudo no que diz respeito ao ensino de PLA.
\end{abstract}

PALAVRAS-CHAVE: Programa de Estudantes-Convênio de Graduação (PEC-G); Português como Língua Adicional (PLA); Relato de experiência; Formação de professores.

ABSTRACT: For more than 50 years, the Brazilian government has been maintaining agreements with developing countries through the Exchange Program for Undergraduate Students (PEC-G), offering vacancies is undergraduate courses in

\footnotetext{
${ }^{1}$ Doutoranda em Estudos Linguísticos pela Universidade Federal de Minas Gerais (UFMG). Email: marcela.linguistica@gmail.com
} 


\section{REVISTA X, Curitiba, volume 13,n.1,p.141-160, 2018 \\ Dossiê Especial: Português como Língua Adicional em contextos de minorias: (co)construindo sentidos a partir das margens BIZON \& DINIZ (Orgs.)}

Brazilian universities for students of nations in agreement. As part of the agreement, Portuguese as an Additional Language (PAL) courses are offered to students from countries which do not have a Certificate of Proficiency in Portuguese for Foreigners (Celpe-Bras) examination center. From the experience report from one of the PAL teachers of the pre-PEC-G, the article questions issues related to the reception observed in an institution which participates in the program, in addition to seeking to deconstruct negative images generally attributed to PEC-G students. Finally, we will discuss some positive experiences in relation to teacher development. The report highlights differences between this program and other exchange agreements, identifies who is often the main responsible for the program and points out possible actions that have the potential to promote positive learning experiences for students and to provide meaningful experiences related to teacher development. On undertaking this study, we seek to know more about the particularities of the PEC-G agreement, deconstruct visions that essentialize students of this group and discuss ways of dealing with the program specificities especially in regard to PAL teaching.

KEYWORDS: Exchange Program for Undergraduate Students (PEC-G); Portuguese as an Additional Language (PAL); Experience report; Teacher training.

\section{INTRODUÇÃO}

Para iniciar este artigo, apresentaremos o contexto de pesquisa mais amplo em que o estudo está inserido. Primeiramente, apresento o Programa de EstudantesConvênio de Graduação (doravante PEC-G) e, em seguida, discorro e problematizo sobre adversidades frequentes na vivência de alguns dos estudantes do programa, sobretudo no ano em que realizam os estudos de Português como Língua Adicional (doravante PLA) no Brasil, por meio de reflexões presentes em narrativas de uma professora no que diz respeito às suas experiências como docente do curso de PLA para o pré-PEC-G. Objetivo investigar alguns sentidos que a professora atribui aos desafios e às ações desenvolvidas no âmbito do curso, além de suas percepções sobre como a experiência docente impactou em sua formação profissional.

Os registros foram gerados por meio de entrevista semiestruturada com uma professora de PLA do convênio PEC-G de uma universidade brasileira localizada no sudeste do país. A professora participante da pesquisa ministrou aulas de PLA específicas para o grupo do pré-PEC-G por três anos durante seus estudos de graduação 
REVISTA X, Curitiba, volume 13,n.1,p.141-160, 2018.

Dossiê Especial: Português como Língua Adicional em contextos de minorias: (co)construindo sentidos a partir das margens BIZON \& DINIZ (Orgs.)

em Letras. A entrevista foi concedida para compor o corpus de minha pesquisa de doutorado em estudos linguísticos, em andamento, aprovada no Comitê de Ética da Universidade Federal de Minas Gerais².

Os excertos selecionados para a análise apontam para a responsabilidade de todos os profissionais responsáveis pelo programa, além de revelarem visões que essencializam o grupo de estudantes do PEC-G, contribuindo, em certa medida, para a promoção de estereótipos e preconceitos a eles direcionados. Na parte final do artigo, apresentaremos narrativas que discorrem sobre as histórias marcantes e experiências positivas com relação à formação profissional.

\section{O PEC-G}

Criado pelo governo brasileiro oficialmente em 1965 e desenvolvido pelo Ministério de Relações Exteriores (doravante MRE) em conjunto com o Ministério da Educação (doravante MEC), o PEC-G estabelece cooperação entre o Brasil e países em vias de desenvolvimento, de forma a manter "acordo de Cooperação Cultural e/ou Educacional e/ou de Ciência e Tecnologia"3. Segundo o Portal do MEC dedicado ao PEC-G ${ }^{4}$, o programa oferece oportunidade de formação superior a estudantes internacionais em cursos brasileiros de graduação. Em contrapartida, os conveniados devem assumir o compromisso de que, ao final dos estudos, retornarão ao seu país de origem a fim de contribuírem com a área na qual se graduaram e, consequentemente, com o desenvolvimento de seus países.

Ainda de acordo o Portal do MEC, o participante deve atender a alguns critérios para que possa ser selecionado e cursar gratuitamente a graduação em universidades públicas (federais e estaduais) e particulares brasileiras, que incluem: ter entre 18 e 23 anos; possuir certificado de conclusão do ensino médio ou curso equivalente; confirmar proficiência em língua portuguesa por meio de certificação em

\footnotetext{
${ }^{2}$ Número do parecer: 2.248.256.

${ }^{3}$ Disponível em:<http://www.dce.mre.gov.br/PECG.html>. Acesso em 03 set. 2017.

${ }^{4}$ Disponível em:<http://portal.mec.gov.br/pec-g>. Acesso em 05 mar. 2018.
} 
REVISTA X, Curitiba, volume 13,n.1,p. 141-160, 2018.

\section{Dossiê Especial: Português como Língua Adicional em contextos de minorias: (co)construindo sentidos a partir das margens BIZON \& DINIZ (Orgs.)}

nível intermediário ${ }^{5}$ (ou superior) no Certificado de Proficiência em Língua Portuguesa para Estrangeiros (doravante Celpe-Bras), além de apresentar comprovação de que tem recursos "suficientes para custear sua manutenção no Brasil: moradia, alimentação, transporte, vestuário, material didático etc."6 O programa prevê que os estudantes conveniados não exerçam trabalhos remunerados, de forma que, muitas vezes, acabam por contar exclusivamente com recursos enviados pela família.

Os estudantes selecionados vindos de países que não contam com posto aplicador do Celpe-Bras têm a oportunidade de ir ao Brasil um ano antes dos estudos de graduação, a fim de realizarem um curso de PLA que objetiva prepará-los para o exame e para o início de seus estudos de graduação em universidades brasileiras. É comum que, nesse primeiro ano no Brasil, tais estudantes ainda não consigam um maior vínculo institucional nas Instituições de Ensino Superior (doravante IES) ${ }^{7}$ - na maior parte das vezes, não recebem, por exemplo, um número de matrícula, o que facilitaria o acesso a alguns serviços universitários, como biblioteca e restaurante universitário, - e apenas farão parte do programa efetivamente após serem aprovados no exame Celpe-Bras. Por esse motivo, referimo-nos a esse período como pré-PEC-G.

Segundo o site do Ministério de Relações Exteriores ${ }^{8}$, os países participantes do PEC-G são, atualmente, 57, divididos entre os continentes africano, asiático e americano (América Latina e Caribe), sendo a África e a América Latina as regiões de onde mais vêm estudantes conveniados ${ }^{9}$. É preciso considerar que, conforme lembram Ruano et al (2006), o custo de vida no Brasil pode ser muito maior do que na maioria dos países africanos e latino-americanos, o que pode favorecer certa vulnerabilidade financeira de alguns participantes. Além disso, há outras situações adversas que

\footnotetext{
${ }^{5}$ De acordo com o site do Instituto Nacional de Estudos e Pesquisas Educacionais Anísio Teixeira (Inep), o Celpe-Bras é outorgado pelo MEC, e é o único certificado brasileiro de proficiência em português como língua estrangeira reconhecido oficialmente. Aplicado desde 1998, é conferido em quatro níveis: intermediário, intermediário superior, avançado e avançado superior. Disponível em: $<$ http://portal.inep.gov.br/celpebras>. Acesso em 05 mar. 2018.

${ }^{6}$ Disponível em:〈http://portal.mec.gov.br/sesu/arquivos/pdf/CelpeBras/manualpec-g.pdf〉 Acesso em 05 mar. 2018.

${ }^{7}$ Isso depende de recursos e iniciativas da instituição responsável pelo programa em cada IES.

${ }^{8}$ Disponível em: <http://www.dce.mre.gov.br/PEC/paises_participantes.html>. Acesso em maio de 2015.

9 Tais números relacionam-se refletem o fato de que ainda são poucos os postos aplicadores do CelpeBras no continente africano e em alguns países da América Latina, com destaque para Honduras, Jamaica, Haiti e Panamá.
} 
REVISTA X, Curitiba, volume 13,n.1,p.141-160, 2018.

Dossiê Especial: Português como Língua Adicional em contextos de minorias:

(co)construindo sentidos a partir das margens

BIZON \& DINIZ (Orgs.)

frequentemente são enfrentadas pelos estudantes do programa, sobretudo no ano em que antecede os estudos de graduação no Brasil. A próxima seção é, portanto, dedicada a essa temática.

\section{ESTUDANTES DO PRÉ-PEC-G: ADVERSIDADES FREQUENTES}

Antes de discorrer sobre algumas adversidades frequentemente enfrentadas por estudantes do pré-PEC-G, esclarecemos que adotamos a perspectiva da Linguística Aplicada Indisciplinar, que procura problematizar e criar inteligibilidade sobre as adversidades com que nos defrontamos (MOITA LOPES, 2006b), possibilitando a criação de "alternativas sociais com base nas e com as vozes dos que estão à margem: os pobres, os favelados, os negros, os indígenas, homens e mulheres homoeróticos, mulheres e homens em situação de dificuldades sociais e outros" (MOITA LOPES, 2006a). Nessa perspectiva, é fundamental considerar a heterogeneidade, a fragmentação e a fluidez do sujeito. Dito de outra forma, apesar de poderem, eventualmente, apresentar algumas características em comum, os estudantes do PEC-G não constituem um grupo homogêneo e imutável.

Posto isso, passo a discorrer sobre alguns desafios frequentes enfrentados pelos estudantes do PEC-G. Para que possam realizar os estudos no Brasil, há, como já sinalizamos, uma condição: a aprovação no Celpe-Bras. Caso não consiga a certificação mínima exigida no exame, o estudante é impedido de fazer a graduação no Brasil, conforme prevê o decreto número 7.948, de 12 de março de $2013^{10}$ :

O candidato reprovado no Celpe-Bras aplicado no Brasil, na forma do § 2o, não poderá ingressar no PEC-G, vedada a prorrogação de seu registro e do prazo de estada no Brasil, conforme disposto na Lei n-_6.815, de 19 de agosto de 1980 e no Decreto n ${ }^{\circ} 86.715$, de 10 de dezembro de 1981.

Desse modo, a aprovação no exame Celpe-Bras pode ter impactos decisivos para o futuro dos estudantes conveniados ao PEC-G. A responsabilidade é, portanto, muito grande, não só dos estudantes e dos professores que atuam no curso de PLA, mas

\footnotetext{
${ }^{10}$ Disponível em: <http://www.planalto.gov.br/ccivil_03/_Ato2011-2014/2013/Decreto/D7948.htm>. Acesso em agosto de 2016.
} 
REVISTA X, Curitiba, volume 13,n.1,p.141-160, 2018.

Dossiê Especial: Português como Língua Adicional em contextos de minorias:

(co)construindo sentidos a partir das margens

BIZON \& DINIZ (Orgs.)

também dos órgãos responsáveis pelo programa, sendo fundamental a realização de pesquisas no âmbito de ensino/aprendizagem e de políticas do programa.

Além da exigência apontada acima, que pode gerar ansiedade devido à grande responsabilidade de aprovação, existem muitos desafios geralmente enfrentados pelos estudantes para que consigam permanecer no Brasil, especialmente ao longo do ano que antecede a sua graduação - período em que participarão do curso de PLA para o préPEC-G em uma das IES conveniadas e se prepararão para, naquele mesmo ano, prestar o exame Celpe-Bras.

Primeiramente, gostaríamos de nos deter ao desafio relacionado ao aspecto social. Como mostram Bizon (2013) e Miranda (2016), por meio das narrativas produzidas em suas pesquisas de doutorado e mestrado, respectivamente, assim como minha própria experiência como professora neste contexto, estudantes conveniados ao PEC-G e inseridos nas universidades relatam, com frequência, histórias marcadas por preconceito, discriminação e invisibilização, por exemplo, em momentos em que são estigmatizados como menos capazes intelectualmente, seja por colegas de graduação, seja por seus próprios professores.

Miranda (2016) exemplifica a situação de uma graduanda haitiana que relatou que, em um trabalho de grupo de uma das disciplinas de seu curso, seus colegas brasileiros não queriam que ela participasse ativamente da apresentação avaliativa solicitada pela professora, reservando-lhe apenas a apresentação do grupo no início do seminário. A estudante considerou que tal atitude revelou a crença de seus colegas de que ela não poderia trazer contribuições para o trabalho do grupo, crença esta que ela interpretou como preconceituosa. Esse é um exemplo que, possivelmente, evidencia que alguns estudantes do PEC-G são estigmatizados pelo olhar da falta, ou seja, muitos discursos feitos sobre eles são marcados por aquilo que, supostamente, não possuem, como se todos não tivessem condições financeiras satisfatórias, ou como se todos tivessem uma escolarização deficitária em seus países, entre outros tipos de discriminação. 
REVISTA X, Curitiba, volume 13,n.1,p.141-160, 2018.

Dossiê Especial: Português como Língua Adicional em contextos de minorias:

(co)construindo sentidos a partir das margens

BIZON \& DINIZ (Orgs.)

Além disso, são também frequentes histórias ligadas à vulnerabilidade financeira envolvendo alguns estudantes do PEC-G, como revela o seguinte excerto da entrevista concedida pela professora participante da pesquisa:

[1]

P: No PEC-G você preocupa se o menino está conseguindo se manter aqui [cidade onde se localiza a IES analisada], se ele está se alimentando bem, se a família dele não está com problemas na África, isso pode impactar a aprendizagem dele aqui, consequentemente o resultado que ele vai ter no Celpe-Bras:: a responsabilidade é maior acredito, no PEC-G, da equipe docente.

O excerto acima reforça os enfrentamentos que alguns dos estudantes do curso vivenciam. Nele, encontramos dois elementos que precisam ser discutidos e problematizados: o fato de que a responsabilidade para a resolução de problemas como dificuldades financeiras recaia sobre a equipe docente e a forma como a professora essencializa o grupo de estudantes. Para refletirmos sobre os dois elementos apontados, vamos organizá-los em duas seções analíticas: (i) Reflexões sobre o papel dos sujeitos envolvidos com o PEC-G e (ii) Representações geralmente associadas aos estudantes do PEC-G.

\section{REFLEXÕES SOBRE O PAPEL DOS SUJEITOS ENVOLVIDOS COM O PEC-}

G

Como já apresentamos anteriormente, uma das exigências para candidatar-se ao programa é a de que o estudante-convênio apresente comprovação de que tem os recursos para se manter financeiramente no Brasil. No entanto, a realidade mostra a dificuldade de alguns estudantes em se manterem no país, visto que, muitas vezes, o recurso enviado pelos responsáveis não é suficiente ou simplesmente não chega, por motivos diversos, como já constatei algumas vezes em minha experiência como 


\section{REVISTA X, Curitiba, volume 13,n.1,p.141-160, 2018. \\ Dossiê Especial: Português como Língua Adicional em contextos de minorias: (co)construindo sentidos a partir das margens BIZON \& DINIZ (Orgs.)}

professora do curso. Relatos da mesma natureza encontram-se nas pesquisas de Bizon (2013) e Miranda (2016) e foram compartilhados em um encontro sobre o pré-PEC-G em $2017^{11}$, revelando que as dificuldades não são exclusivas do contexto analisado, mas são frequentes e atingem estudantes de diferentes IES e de diferentes anos. Muitas vezes, quando o estudante apresenta dificuldades financeiras, são os professores de PLA que se mobilizam para oferecer auxílio. Assim, além de responsáveis por preparar e ministrar aulas, muitas vezes os docentes possuem preocupações que ultrapassam o contexto de ensino/aprendizagem, como reiterado na narrativa 1.

Essas dificuldades financeiras são agravadas pelo fato de que os estudantes do pré-PEC-G não têm à sua disposição mecanismos de ajuda financeira por parte dos órgãos responsáveis pelo programa, como também lembram Bizon (2013) e Miranda (2016). As autoras citam tentativas individualizadas de IES que buscam, por exemplo, conseguir auxílio alimentação e vagas nas moradias estudantis, a despeito de entraves burocráticos advindos do fato de que tais estudantes ainda não têm um vínculo efetivo com as IES. Como professora do curso do pré-PEC-G, também presenciei situações em que estudantes, sem condições de arcar com os gastos de aluguel, contaram com a ajuda da comunidade, de dentro e de fora da academia, como a arrecadação de dinheiro para cobrir os gastos de moradia, por exemplo.

O MRE, por sua vez, parece não se preocupar em estruturar formas de apoio aos estudantes pré-PEC-G, sob o argumento de que cabem aos responsáveis pelos alunos o compromisso de mantê-los no Brasil. Opomos-nos a esse argumento, visto que, na prática, a manutenção das necessidades básicas dos estudantes vem se mostrando, muitas vezes, ineficiente. Conforme afirma Bizon (2013), há falhas na regulamentação do documento comprobatório de renda familiar que confirma que os pais ou responsáveis têm condições de custear a vida dos estudantes no território brasileiro.

\footnotetext{
11 Refiro-me ao encontro entre coordenadores e professores do curso de PLA para o pré-PEC-G de diferentes IES do Brasil, ocorrido na Universidade Federal do Paraná (UFPR) em novembro de 2017. Nessa ocasião, houve troca de experiências sobre três temas: (i) Acolhimento ao/à estudante pré-PEC-G; (ii) Diretrizes curriculares e material didático para o/a estudante pré-PEC-G; e (iii) Vínculo institucional do/da estudante pré-PEC-G. A partir de tais discussões, os participantes enviaram uma carta ao MEC e ao MRE, a fim de solicitar providências quanto aos problemas mais urgentes que, na visão dos participantes do encontro, prejudicam o bom funcionamento do convênio.
} 
REVISTA X, Curitiba, volume 13,n.1,p.141-160, 2018.

Dossiê Especial: Português como Língua Adicional em contextos de minorias: (co)construindo sentidos a partir das margens BIZON \& DINIZ (Orgs.)

Como mostra a pesquisadora, apenas a assinatura do documento não garante que o dinheiro que chega ao Brasil seja suficiente para cobrir as despesas básicas do estudante ou, em alguns casos, dinheiro algum é enviado. Podemos afirmar que fatos dessa natureza frequentemente geram situações degradantes e humilhantes para os estudantes, ferindo sua dignidade.

Para evitar esse tipo de situação e não formar apenas a elite dos países participantes, que detém de recursos financeiros para a manutenção dos estudantes no Brasil, consideramos necessário que o MRE e o MEC estudem formas de apoiar financeiramente os estudantes, desde o pré-PEC-G. Esta ação mostra-se fundamental devido à proposta do convênio, que visa à cooperação entre os países participantes.

$\mathrm{Na}$ atual configuração do programa, conforme mencionamos acima, são os professores quem, frequentemente, dão apoio aos estudantes no que diz respeito ao seu acolhimento, muitas vezes com o suporte de familiares e da comunidade em geral. No entanto, chamamos a atenção para a importância de relatar tais problemas aos órgãos responsáveis pelo PEC-G, pois, caso esses problemas não sejam reportados às instituições hierarquicamente superiores, cria-se a ilusão de que não há falhas na implementação do acolhimento do programa e de que tudo está funcionando bem. Desse modo, saliento a necessidade de reflexão sobre as atitudes tomadas nas IES, para que cada situação de dificuldade chegue aos órgãos competentes e melhorias possam ser realizadas, de modo a acolher verdadeiramente o estudante-convênio.

Além disso, é importante, diante dos problemas relatados, a promoção de discussões sobre possível deficiência nas diretrizes do programa, que não oferece condições básicas que amparem e assegurem o bem-estar dos estudantes, como seguro saúde, auxílio moradia e alimentação. Considerando que o programa é regido pelo MRE, pelo MEC e pelas IES, há indícios de falta de organização entre essas instâncias para garantir questões essenciais para a vivência desses estudantes no Brasil.

\section{REPRESENTAÇÕES GERALMENTE ASSOCIADAS AOS ESTUDANTES DO PEC-G}


REVISTA X, Curitiba, volume 13,n.1,p. 141-160, 2018.

Dossiê Especial: Português como Língua Adicional em contextos de minorias:

(co)construindo sentidos a partir das margens

BIZON \& DINIZ (Orgs.)

No excerto 1, anteriormente apresentado, a professora enumera vulnerabilidades supostamente "intrínsecas" aos estudantes do PEC-G, sobretudo com relação à manutenção de suas necessidades básicas no Brasil.

Primeiramente, chamamos a atenção por ela apenas se referir à África, colocação que sugere que todos os estudantes desse continente passam pelas mesmas dificuldades. Há também um apagamento dos estudantes de países que não são do continente africano e que também integram o grupo, inclusive dos anos em que a professora atuou como docente do curso. São frequentes discursos marcados por totalização que relacionam o estudante do PEC-G à África, como se o "estudante africano" fosse o "modelo" do programa. Tal relação não se associa unicamente com questões quantitativas, visto que há muitos estudantes das Américas do Sul e Central, por exemplo, que também são participantes do PEC-G. Essa representação também pode ser percebida no excerto a seguir:

[2]

P: O PEC-G, ele:: ele não vem só com o aluno, ele vem com o aluno e a vulnerabilidade que ele tem. Não só para poder:: como ser humano para poder aprender, mas vem com uma dificuldade financeira, vem com uma dificuldade de adequação cultural. Você pode achar isso em uma disciplina da graduação? Pode, lá você reconstrói, mas o seu contato é menos pessoal com o aluno, muito mais técnico do que no PEC-G.

Apesar de a docente apontar para questões importantes, como os problemas relacionados às dificuldades financeiras que geralmente permeiam esses estudantes, seu relato promove reducionismos e pressupõe essencialização e homogeneização, apresentadas como inerentes e constitutivas do grupo. Esse rótulo reafirma o olhar da falta geralmente associado a esses estudantes, transformando-os em minorias marginalizadas, e reforçando uma visão estereotipada desse grupo. Para promover acolhimento de forma respeitosa, é preciso, como aponta Maher (2007b, p. 2), “entender o diferente em sua complexidade", evitando abrangências que evocam estereótipos.

Além disso, quando a docente se refere à "dificuldade de adequação cultural", podemos inferir que assume, em certa medida, uma perspectiva assimilacionista em que o estudante deveria ter certa obrigação de aprender as regras culturais do Brasil, o que poderia sugerir que as construções culturais dos estudantes africanos, como ela se 


\section{REVISTA X, Curitiba, volume 13,n.1,p.141-160, 2018. \\ Dossiê Especial: Português como Língua Adicional em contextos de minorias: (co)construindo sentidos a partir das margens BIZON \& DINIZ (Orgs.)}

refere, não seriam adequadas e eles tivessem de assimilar as que encontram no Brasil. Essa relação entre construções culturais brasileiras e construções culturais de seus próprios países é considerada, no discurso da docente, a partir de uma lógica binária "que não permite compreender a complexidade dos agentes e das relações subtendidas em cada polo, nem a reciprocidade das inter-relações, nem a pluralidade e a variabilidade dos significados produzidos nessas relações" (FLEURI, 2003, p. 24 apud MAHER, 2007b, p. 21). Para Maher (2007b, p. 20), “o que ocorre na sala de aula não é simples justaposição de culturas", uma vez que as identidades culturais de professores e estudantes esbarram e tropeçam umas nas outras a todo momento. Segundo a autora (2007a), o encontro com o outro, com o diferente é difícil e complexo e exige preparação, sobretudo quando se trata do professor, que é a figura de referência para os estudantes que estão iniciando sua vida em outro país. Assim, defendemos que o papel do docente é mostrar diferentes caminhos existentes para que os estudantes respeitem a todos. É evidente que há princípios do professor que não serão mudados, mas isso não deve obrigar o outro, o estudante, a seguir esse mesmo princípio. O professor não pode impor uma posição ou regra cultural, mas tem de reconhecer a posição do estudante, assim como esse também deve reconhecer a posição do professor.

Outro estigma usualmente relacionado aos estudantes do PEC-G é o de sua escolarização. De acordo com o manual do programa ${ }^{12}$, a exigência de que obtenham a certificação de nível intermediário tem como objetivo "solucionar o problema recorrente do fraco domínio da língua portuguesa, especialmente da parte dos participantes provenientes de países hispanófonos, desde o início do Programa, com sérios prejuízos para seu desempenho acadêmico".

A narrativa da professora participante desse estudo retratada abaixo revela o estigma a que estudantes estão frequentemente sujeitos e como têm lidado com essas discriminações com o auxílio do curso de PLA preparatório para o Celpe-Bras. Após discorrer sobre as dificuldades de inserção de alguns estudantes na sociedade brasileira devido a construções culturais, sobretudo com relação à posição da mulher na

\footnotetext{
${ }^{12}$ Disponível em: <https://pt.scribd.com/document/134398246/Manual-Pec-g>. Acesso em: 05 mar. 2018.
} 
REVISTA X, Curitiba, volume 13,n.1,p.141-160, 2018.

\section{Dossiê Especial: Português como Língua Adicional em contextos de minorias: (co)construindo sentidos a partir das margens BIZON \& DINIZ (Orgs.)}

sociedade, perguntei-lhe se o curso, que conta com o trabalho de cinco docentes ${ }^{13}$, provocou deslocamentos nos estudantes, no intuito de respeitarem as construções culturais típicas do Brasil. A professora responde positivamente, exemplificando por meio da experiência de um de seus ex-alunos do pré-PEC-G, como vemos nos excertos a seguir:

[3]

PP: E você acha que o curso, com essa:: a integração das professoras, isso ajudou eles a respeitarem a cultura do Brasil?

PA: Um desses alunos inclusive, ele se interagiu, ele se deu muito bem não só pelo esforço nos estudos, mas ele se tornou muito conhecido por dar aulas particulares e tudo, não só pelo pelo:: estudo pelo:: esforço, mas pela interação que ele construiu na unidade acadêmica em que ele estuda. Então isso para mim, não sei, a impressão que eu tenho é que isso já é um sinal de que ele conseguiu se integrar, não só pela parte intelectual, mas pela parte pessoal também, pela socialização.

PP: E você vê que esse resultado final foi uma consequência também do que foi ensinado no primeiro ano, no curso de português?

PA: Com certeza, com certeza. E eu vejo inclusive esse aluno, há pouco tempo eu conversei com ele, eu vejo que até o posicionamento desse aluno em relação às pessoas que têm preconceito, por exemplo, com outros negros, contra quem é da África, é uma posição mais moderada. É:: e ele mostra, porque ele está mostrando na prática que:: o lugar efetivo deles sem precisar ser agressivo. "Não, não é nada disso, na África não tem aquilo não". Ele mostra pelo que ele é, que a África não é o que as pessoas pensam, que o fato dele ser negro não tem que colocar ele abaixo de ninguém, então ele parou com esse tom mais agressivo que eu acho que é você render muito com pessoas, né, e mostrou, pela inteligência dele, sendo negro, vindo da África, vindo de um sistema educacional que as pessoas não esperam que seja tão eficiente e foi capaz de superar e vencer. Então ele mostrou, desde uma perspectiva muito diferente, que na condição dele, de negro e africano, ser capaz de:: de se impor. Ele se impôs pela habilidade que ele tem, então ele não precisou usar mais a agressividade, ele usou simplesmente o dom que ele tem que independe da raça, da cultura de onde ele venha. Isso que mais me impressionou. E com certeza isso vem também a partir do curso.

O recorte acima desvela uma contradição: a professora diz que o fato de ser negro não coloca o estudante abaixo de ninguém, visão ainda recorrente em nossa sociedade. Contudo, o relato que se segue, em destaque, pode ser interpretado de forma

\footnotetext{
${ }^{13} \mathrm{O}$ curso analisado é ministrado por cinco professoras, estudantes de graduação e pós-graduação da IES em questão.
} 


\section{REVISTA X, Curitiba, volume 13,n.1,p.141-160, 2018. \\ Dossiê Especial: Português como Língua Adicional em contextos de minorias: (co)construindo sentidos a partir das margens BIZON \& DINIZ (Orgs.)}

negativa. Esse excerto aponta para o olhar da falta, já citado anteriormente, na medida em que pressupõe uma hierarquização, que coloca um sistema educacional africano como "menos eficiente" que o brasileiro, o que estaria na origem de dificuldades que os alunos precisariam “superar" para "vencer”. Desse modo, a própria professora apresenta um posicionamento que parece também colocar o estudante em um lugar menor, visto que ele é negro e africano ("sendo negro, vindo da África"). Além disso, a palavra "inteligência" é uma escolha lexical delicada, pois abre margem para a interpretação de que ela reconhece nesse estudante uma exceção, como se a inteligência não fosse uma qualidade comum destes alunos, o que vem a reforçar um lugar inferior para os estudantes de países africanos.

Antes de desferir esse tipo de discurso, é importante reconhecer as singularidades desses estudantes, como argumenta Maher (2007a, p. 265), que traz para o centro do debate a necessidade de preparação para conviver com a diferença "de forma mais informada e respeitável possível", de forma a contribuir para igualdade de oportunidades para os grupos minoritarizados e desprestigiados socialmente.

Para encerrar essa seção, é importante apontar que a entrevista dessa professora é culturalmente marcada por um discurso muito forte na sociedade brasileira. Procuramos desconstruí-lo e desnaturalizá-lo, buscando promover a quebra de estereótipos e de preconceitos. Conforme afirma a escritora nigeriana Chimamanda Adichie, "se repetirmos uma coisa várias vezes, ela se torna normal. Se vemos uma coisa com frequência, ela se torna normal" (ADICHIE, 2015 p. 16). É preciso que interrompamos esse tipo de discurso para que deixe de ser normal.

Apesar de a narrativa da professora participante evidenciar posicionamentos que, a nosso ver, precisamos problematizar, podemos encontrar em suas narrativas experiências marcantes que buscam evocar uma importante relação entre as culturas, como veremos na seção a seguir, na qual a docente narra experiências significativas para sua formação.

\section{FORMAÇÃO DE PROFESSORES: EXPERIÊNCIAS MARCANTES}


REVISTA X, Curitiba, volume 13,n.1,p.141-160, 2018.

Dossiê Especial: Português como Língua Adicional em contextos de minorias:

(co)construindo sentidos a partir das margens

BIZON \& DINIZ (Orgs.)

Para finalizar, destacaremos o que foi mais marcante durante o trabalho da professora participante: as atividades e projetos realizados extraclasse. $\mathrm{O}$ curso em que a professora atuou vem promovendo, em suas últimas edições $(2015,2016,2017)$, bem como na edição de 2018, projetos realizados em parceria com escolas de ensino médio e fundamental e com a própria universidade anfitriã, a fim de aproximar os conveniados do PEC-G com estudantes brasileiros. São projetos que visam à aprendizagem mútua, de modo que os brasileiros possam conhecer mais sobre os países da América Latina, da África e de suas múltiplas culturas, e suas relações com as construções culturais brasileiras, a fim de valorizar a diversidade étnica, minimizando conflitos sociais e preconceitos. Além disso, buscam desenvolver a autonomia dos estudantes para que possam se posicionar diante dos enfrentamentos da vida, em situações de preconceito e discriminação que, não raras vezes, vivenciam. Por isso, a inquietação da equipe docente responsável pelo curso analisado sobre o entendimento de que apenas aulas preparatórias para o exame Celpe-Bras não são suficientes para os estudantes. Quando indagada sobre a experiência mais marcante em sua vivência como docente do PEC-G, a professora participante cita iniciativas como os projetos e atividades apresentadas no início dessa seção:

[4]

P: A experiência (...) que lembro, que me marcou muito, que a gente contou com o apoio das:: foi a gente ter visitado, foram duas, na verdade, as principais: foi a organização do teatro Pelo Mundo, que exigiu a mobilização de todas as professoras, (...) uma colaboração maior entre elas e ao mesmo tempo uma motivação deles em puxar nossa participação também e conduziu muito bem a produção do teatro, então a organização do teatro Pelo Mundo me chamou muito a atenção.

A primeira delas é o projeto Pelo Mundo, desenvolvido com a turma de estudantes do ano de 2015, que é tema da dissertação de Miranda (2016) e do artigo da mesma autora presente neste dossiê. O projeto surgiu como forma de trabalhar as inquietações dos estudantes decorrentes de ideias preconcebidas dentro da sala de aula, que englobava estudantes de diferentes países da África e de América Central. Tal iniciativa não teve impacto apenas no ano de 2015, mas também nos anos posteriores por meio de outras atividades que foram e vem sendo promovidas desde então, que 
REVISTA X, Curitiba, volume 13,n.1,p.141-160, 2018.

\title{
Dossiê Especial: Português como Língua Adicional em contextos de minorias: (co)construindo sentidos a partir das margens BIZON \& DINIZ (Orgs.)
}

também foi citada pela professora como uma das experiências mais marcantes durante o período em que trabalhou como docente no curso de PLA para o pré-PEC-G:

\begin{abstract}
[5]
P: O trabalho sobre o preconceito, que as professoras fizeram em parceria com um colégio público aqui de [cidade onde se localiza a IES analisada], eu vi o empenho delas em querer mobilizar toda a equipe de professores para poder desenvolver esse trabalho com os alunos. Foi super produtivo, é:: mostrou que é possível fazer, com muito esforço, mas é possível, né, me levou a pensar em aspectos que eu não tinha pensado na prática.
\end{abstract}

A atividade mencionada no excerto acima foi apenas uma das desenvolvidas no curso de 2016. Realizada com alunos de seis a doze anos de uma escola pública de ensino fundamental da cidade de Belo Horizonte, foi impulsionada graças ao êxito do projeto Pelo Mundo. Essa atividade envolvia questões como "africanidades" e racismo, temática amplamente trabalhada no curso de PLA de 2016 e teve como principais objetivos: (i) a reflexão sobre o conceito da imigração africana e outros países para o continente americano; (ii) a compreensão das religiões de matizes africanas na cultura brasileira; (iii) o entendimento de que o estudo das religiões africanas pode minimizar os conflitos sociais e o preconceito sobre a cultura afro-brasileira; (iv) a valorização das características étnicas do homem negro, entendendo que as diferenças existem, devem ser respeitadas e que o conceito de belo é relativo. Tais ações perpassam pelas premissas do Letramento Crítico, cujas bases se sustentam em valores revolucionários, incluindo a pedagogia crítica de Paulo Freire (1996; 2006; 2007). Essa perspectiva de ensino considera a língua como instrumento de poder e transformação social, concebendo a elaboração de materiais e o agir em sala de aula de acordo com o que acontece e envolve a realidade e a prática social dos aprendizes (MATTOS; VALERIO, 2010). Desse modo, como destacam as autoras, seu principal objetivo é desenvolver a consciência crítica dos estudantes, que aprendem a língua para transformar a si mesmos e a sociedade. Esta abordagem, que vai além da visão da língua como código linguístico, enfatiza o processo de construção coletiva de sentidos, da mesma maneira como acontece em contextos comunicacionais reais.

Nesse sentido, o processo de leitura pelo qual os aprendizes são submetidos extrapolam a percepção de diferentes perspectivas e "(re)inscreve suas posições 
REVISTA X, Curitiba, volume 13,n.1,p.141-160, 2018.

Dossiê Especial: Português como Língua Adicional em contextos de minorias: (co)construindo sentidos a partir das margens

BIZON \& DINIZ (Orgs.)

enquanto sujeito e as representações sociais de sua identidade" (JORDÃO; FOGAÇA, 2007, p. 90). Nessa perspectiva, a formação do professor se faz fundamental, pois é ele o responsável por proporcionar, aos estudantes, oportunidades de construção e negociação de significados coletivamente, de modo que possam "rever suas crenças" e “questionar as implicações de suas visões de mundo" (ibidem, p. 91).

Logo, a equipe de professoras busca promover um curso em que os envolvidos desempenhem papel ativo por meio de projetos e atividades desenvolvidas com escolas de ensino fundamental e médio, assim como em projetos realizados dentro da própria universidade onde se dá o curso, uma vez que se acredita nos benefícios do trabalho em conjunto, como expresso por Figueiredo (2007) ao citar os estudos de Long e Porter (1985) e Coelho (1992), que demonstram que a "aprendizagem colaborativa maximiza a aquisição de L2" (p. 3). Assim, podemos ressaltar os benefícios desse tipo de projeto para os estudantes internacionais e para os estudantes brasileiros, além de suas contribuições para a aproximação entre a universidade e a escola. Cumpre destacar, ainda, que iniciativas dessa natureza contribuem para a visibilização das vozes dos estudantes, pois, embora o PEC-G seja um dos convênios que mais trazem estudantes internacionais para as universidades brasileiras - totalizou mais de seis mil pessoas na última década ${ }^{14}$ - e tenha mais de cinquenta anos de duração, ainda é pouco conhecido, mesmo no contexto acadêmico.

Esse estudo é uma evidência de que o projeto Pelo Mundo promoveu significativas transformações para os estudantes e professores envolvidos, já que teve extensão em outras atividades, e continua a contribuir para a manutenção e promoção da educação do entorno para a interculturalidade (MAHER, 2007a), perspectiva que evoca a relação entre as culturas sem ignorar as relações de poder existentes entre elas. Ainda é comum que o espaço dispensado à diversidade cultural seja limitado a representações bastante fetichizadas e trivializadas, evocando apenas aspectos da cultura material, como gastronomia, danças, músicas e demais expressões artísticas, manifestações que, segundo Maher (op. cit.), estão na superfície das construções culturais, não sendo, em si próprias, suficientes para garantir o respeito à pluralidade cultural. As atividades

${ }^{14}$ Disponível em:<http://www.dce.mre.gov.br/PEC/G/historico.php> Acesso em agosto de 2016. 
REVISTA X, Curitiba, volume 13,n.1,p.141-160, 2018.

Dossiê Especial: Português como Língua Adicional em contextos de minorias: (co)construindo sentidos a partir das margens

BIZON \& DINIZ (Orgs.)

mencionadas buscam dar um passo a mais, pois pretendem contribuir no empoderamento dos estudantes, que, para Maher (op. cit.) decorre de três cursos de ação: sua politização, o estabelecimento de legislações a eles favoráveis e a educação do entorno para o respeito à diferença. Isso significa uma maior possibilidade de inserção dos estudantes do PEC-G no espaço acadêmico e em outros espaços sociais brasileiros.

\section{CONSIDERAÇÕES FINAIS}

Meu objetivo, neste estudo, foi conhecer as percepções de uma professora de PLA para o pré-PEC-G a fim de discutir algumas das dificuldades impostas por esse contexto de ensino/aprendizagem. As narrativas da professora participante apontaram para questões a serem problematizadas. Além disso, conhecemos algumas ações realizadas no curso estudado e os impactos que trouxeram para a formação da participante da pesquisa.

Uma primeira reflexão que fizemos diz respeito às responsabilidades que alguns professores assumem para ajudar estudantes que eventualmente possam estar passando por dificuldades financeiras, por exemplo. Acredito que é necessária uma melhor distribuição de tarefas de cada integrante da equipe do PEC-G, isto é, os professores, os responsáveis pelo programa dentro da instituição de acolhimento e o MEC e o MRE, órgãos do governo responsáveis por sua criação e manutenção. Assim como foi apontado na carta elaborada no encontro pré-PEC-G promovido pele UFPR em 2017 e em alguns dos recortes analisados neste artigo, há muitos problemas envolvendo o acolhimento dos estudantes do PEC-G, para os quais o MEC e o MRE devem se atentar a fim de que o programa possa funcionar de maneira mais efetiva e os estudantes não passem por situações de vulnerabilidade que firam sua dignidade.

Pudemos refletir também, por meio do relato da professora participante, sobre os desafios que enfrentou durante sua experiência docente e que impactaram em sua formação. Tais desafios englobam aspectos como o estigma e o preconceito que os estudantes desse programa geralmente vivenciam, sejam aqueles causados por serem maiormente negros, ou pela falta de conhecimento de muitos brasileiros quanto às 


\section{REVISTA X, Curitiba, volume 13,n.1,p.141-160, 2018. \\ Dossiê Especial: Português como Língua Adicional em contextos de minorias: (co)construindo sentidos a partir das margens BIZON \& DINIZ (Orgs.)}

culturas de seus países. Os excertos analisados também evidenciam que os estudantes do PEC-G são, muitas vezes, estigmatizados pelo olhar da falta, isto é, muitos discursos sobre eles são marcados por aquilo que, em tese, eles não possuiriam, como acontece quando se pressupõe que não tiveram uma escolarização adequada antes de chegarem ao Brasil. Diante de tais estigmas, a narrativa da professora aponta para a importância de projetos e atividades que buscam a promoção da educação do entorno para a interculturalidade no desenvolvimento do curso de PLA para o pré-PEC-G, uma vez que tais experiências foram as mais impactantes em sua formação como professora de PLA para o referido grupo.

Por fim, nossos registros de pesquisa trazem evidências de contradições: ao mesmo tempo em que as atividades e os projetos desenvolvidos buscam desconstruir estereótipos e preconceitos relacionados aos estudantes e a seus países de origem e foram importantes para a formação da professora, narrativas da mesma docente acabam, em certos momentos, por essencializar e homogeneizar esse grupo de alunos. Isso aponta para a necessidade de maior preparação nos cursos de graduação em Letras, já que os currículos pouco incluem questões como estudos de grupos minoritarizados, por exemplo, tão importantes não apenas para o ensino de PLA, mas também para o ensino de línguas de maneira geral.

Assim como Maher (2007a, 2007b), acreditamos na importância de ter em vista as singularidades desses estudantes, indo além da mera tolerância das diferenças. Desse modo, os projetos que vêm sendo desenvolvidos, para além de existirem como micropolíticas, precisam ser referendados e ampliados pelas instituições - MRE e IES como parte efetiva de um programa de promoção do ensino de PLA para a interculturalidade para o pré-PEC-G.

\section{REFERÊNCIAS}

ADICHIE, C. N. Sejamos todos feministas. Tradução: Christina Baum. São Paulo: Companhia das Letras, 2015.

BIZON, A. C. C. Narrando o exame Celpe-Bras e o convênio PEC-G: a construção de territorialidades em tempos de internacionalização. $415 \mathrm{f}$. Tese (Doutorado em Linguística Aplicada) - Instituto de Estudos da Linguagem, Universidade Estadual de Campinas, Campinas. 2013. 
REVISTA X, Curitiba, volume 13,n.1,p.141-160, 2018.

Dossiê Especial: Português como Língua Adicional em contextos de minorias:

(co)construindo sentidos a partir das margens

BIZON \& DINIZ (Orgs.)

COELHO, E. Cooperative learning: foundation for a communicative curriculum. In: KESSLER, C. (Ed.). Cooperative language learning: a teacher's resource book. New Jersey: Prentice Hall Regents, 1992, p. 31-49,

FIGUEIREDO, F. J. Q. A colaboração como uma forma de promover a aprendizagem de língua estrangeira. In: CONGRESSO INTERNACIONAL DA ABRAPUI, 1., 2007, Belo Horizonte. Anais... Belo Horizonte: Universidade Federal de Minas Gerais, 2007.

FLEURI, R. M. Intercultura e Educação. Revista Brasileira de Educação, n. 23, p. 1635, mai/jun/jul/ago 2003.

FREIRE, P. Pedagogia da autonomia: saberes necessários à prática educativa. São Paulo: Paz e Terra, 1996.

Pedagogia do oprimido. 44. ed. São Paulo: Paz e Terra, 2006.

Pedagogia da autonomia. 13. Ed. São Paulo: Paz e Terra, 2007.

JORDÃO, C. M.; FOGAÇA, F. C. Ensino de inglês, letramento crítico e cidadania: um triângulo amoroso bem-sucedido. Línguas e Letras, v. 8, n. 14, p. 79-105, 2007.

LONG, M. H.; PORTER, P. A. Group work, interlanguage talk, and second language acquisition. TESOL Quarterly, v. 19, n. 2, p. 207-228, 1985.

MAHER, T. M. A Educação do Entorno para a Interculturalidade e o Plurilinguismo. In: KLEIMAN, A. B.; CAVALCANTI, M. C. (orgs.) Lingüística Aplicada: suas Faces e Interfaces. Campinas, SP: Mercado de Letras, 2007a, p. 255-270.

MAHER, T. M. Do Casulo ao Movimento: a suspensão das certezas na educação bilíngüe e intercultural. In: CAVALCANTI, M. C.; BORTONI-RICARDO, S. M. (orgs.) Transculturalidade, linguagem e educação. Campinas, SP: Mercado de Letras, , 2007b, p. 67-94.

MATTOS, A. M. de A.; VALÉRIO, K. M. Letramento crítico e ensino comunicativo: lacunas e intersecções. RBLA, Belo Horizonte, v. 10, n. 1, p. 135-158, 2010. Disponível em: <http://www.periodicos.letras.ufmg.br/rbla/arquivos/96.pdf>. Acesso em: 21 abril 2015.

MIRANDA, Y. C. C. Projeto "Pelo Mundo": a configuração de uma política linguística em um curso de português como língua adicional para candidatos ao programa de estudantes-convênio de graduação (PEC-G). Dissertação (Mestrado em Linguística Aplicada) - Faculdade de Letras, Universidade Federal de Minas Gerais, Belo Horizonte, 2016. 
REVISTA X, Curitiba, volume 13,n.1,p.141-160, 2018.

Dossiê Especial: Português como Língua Adicional em contextos de minorias:

(co)construindo sentidos a partir das margens

BIZON \& DINIZ (Orgs.)

MOITA LOPES, L. P. Linguística Aplicada e vida contemporânea: problematização dos construtos que têm orientado a pesquisa. In: MOITA LOPES (Org.). Por uma linguística aplicada INdisciplinar. São Paulo: Parábola, 2006a, p. 85-107

MOITA LOPES, L. P. Uma linguística aplicada mestiça e ideológica: interrogando o campo como linguista aplicado. In: MOITA LOPES (Org.). Por uma linguística aplicada INdisciplinar. São Paulo: Parábola, 2006b, p. 13-44,

RUANO, B. P. et al. O Programa Estudante-Convênio de Graduação (PEC-G) no CelinUFPR: uma experiência de ensino. In: RUANO, B. P; B. P.; SANTOS, J. M. P. S.; SALTINI, L. M. L. (orgs.) Cursos de português como língua estrangeira no CELINUFPR: Práticas docentes e experiências em sala de aula. Curitiba: Ed. UFPR, 2016, p. 199-228. 